The Journal of SPORT, 2014, 3(2), 221-245

(C) Kent State University

\title{
You Have the Right to Tweet, But It Will Be Used Against You: Balancing Monitoring and Privacy for Student-Athletes
}

\author{
Lauren McCoy \\ Western Kentucky University
}

\begin{abstract}
In recent years, social networking has taken on new levels of importance in our society. The impact of social networking has had a major effect on sport media because these sites allow 24/7 contact with athletes for fans and media. While there are many advantages to social media, this constant contact could lead to public relations issues for sports organization, in particular, for universities whose student-athletes may not realize the impact of their words on social media. The first instinct of many is to monitor the information being released via social media by their athletes, but the growing legal climate towards privacy elicits the need to monitor with caution. The purpose of this article is to examine university social media policies and regulation trends as they relate to new privacy regulations that limit the boundaries of monitoring in connection to student-athletes.
\end{abstract}


Interest in social media platforms continues to grow as the instant availability of the Internet expands beyond our homes and computers. Facebook and Twitter, two of the most popular social media platforms, are actively used by 1.23 billion and 241 million users respectively. Active usage is defined by users logging into the social media site at least once a month (Sherman, 2014). These social networking sites allow people to stay in touch, whether they're in the house next door or in another country, and have had a profound effect on the way media, both news and sport, is covered in the U.S. The instantaneous nature of social networking allows news stories to be published both nationally and internationally with the click of a single button. This inundation of information available through social networking sites has created a new form of media that has widespread use in sport: social media. Further, these sites provide $24 / 7$ access to athletes for the media and fans of the team/organization.

While there are many benefits to social networking sites, recent controversies, as told through social media, illicit the need for caution. In May of 2013, a football player at Columbia University in New York was charged with a hate crime after allegedly threatening and taunting another student with racial slurs (Patterson, 2013). This arrest exposed a series of racially insensitive and sexually explicit tweets between the accused and other members of the Columbia University Football team. A collection of 46 posts made on Twitter (also known as tweets) established a record of anti-gay and racially motivated statements made over a series of weeks by members of the football team (Schwab, 2013). This type of news provides embarrassment to any organization, especially an educational institution where we hope to encourage diversity and acceptance. The embarrassment caused by events like these is only compounded by the instant accessibility to private thoughts and conversations through social media. Unfortunately, these types of social networking related controversies are not uncommon. Anyone associated with sport, whether he or she is a professional athlete, 
coach, or student-athlete is in danger of social media commentary affecting their personal and professional futures.

Social media platforms are particularly dangerous for student-athletes, as the above example shows. While these studentathletes are often very well-known by those that follow their particular sport, they are often blind to the need for caution and choosing your words carefully as a celebrity. The communications that led to arrest and other troubles for those Columbia University athletes were likely meant to be private communication among friends. However, the public nature of social networking does not often allow for privacy, a concept that many social networking users often fail to grasp. When student-athletes use social networking sites, their main purpose is to stay in contact with friends and family, communicate with followers and to access information (Browning \& Sanderson, 2012). That primary focus on personal communication can make it difficult for those who have achieved online celebrity status to visualize the line between public and private communication.

The public visibility of social media combined with the desire to communicate with friends and family has led to decisions that affect the professional future of many, particularly for studentathletes. In an attempt to avoid negative press, schools and universities have begun to monitor the social media activity of student-athletes to weed out what they deem to be inappropriate behavior. These policies tend to be stricter in terms of monitoring and the resulting consequences for student-athletes (Sanderson, 2011). In 2012, the University of Michigan stopped recruiting cornerback Yuri Wright due to the derogatory comments he made on Twitter. Wright was also expelled from his high school for these comments (Staples, 2012). The devastating consequences associated with social media monitoring for student-athletes has led to the development of new laws meant to protect student-athletes' social media privacy.

As our use of the internet expands, so too has legislation to protect the privacy rights of internet users. Social media privacy 
rights were first targeted towards employees who were being asked by employers for their social media user names and passwords to monitor the content (House Bill 964, 2012). Employees were typically consenting to this social media access for fear of negative employment impacts. While it does take time, the law eventually catches up to technology. Social media is not inherently private, but those using social media platforms deserve a modified sense of privacy adapted to this new technology (Poore, 2013).

The continued growth of social media aggravates the perceived danger associated with these sites by those in power, leading to monitoring and appropriate punishments for misdeeds. But this monitoring cannot be done without thinking of the legal ramifications. Social networking accounts, especially those not made publicly available, are entitled to some form of privacy under the law in many states. Most recently, this social media legislation has focused on the privacy rights of students and a successful college program must be wary of the legal ramifications of monitoring student-athlete social networking usage. While the majority of student-athletes may not be concerned with what their coach or their school sees on their Facebook or Twitter accounts, they may be entitled to certain levels of privacy under the law and a school will have limited arguments if their monitoring policies are ever challenged in court.

The purpose of this article is to highlight the impact of privacy law on existing social media monitoring trends. These trends establish a sample to understand how colleges are monitoring student-athlete online content. Comparing these trends with the parameters of existing law provides a hypothetical response should a student-athlete ever challenge their university's social media policies. This article focuses on student-athletes due to the harsh punishments given to student-athletes for social media miscues versus the response given to an employee. While an employee may lose their job for comments posted on social media, a student-athlete could lose their scholarship along with their ability to play college sports for any NCAA institution. Additionally, because university 
social media policies are directly primarily towards the studentathlete, the better legal comparison involves those policies meant to protected the rights of students.

This article will identify the current trends for monitoring student-athlete social networking activity including the common practice methods used by universities. Next, this article will highlight the history of privacy law and social media legislation as it affects students. This examination into privacy law will focus on the wordings of each law and will propose a potential interpretation based on the elements of the law to determine the legal viability of each monitoring trend. Understanding what is banned under current law and where these laws currently exist allows universities to create better strategies for monitoring; and comparing existing social media policy within the current structure of the law will provide universities a model to regulate effectively within the parameters of the law.

\section{Trends in Social Networking Monitoring and Regulation}

Social media monitoring exists at both the professional and educational areas of American society. These monitoring efforts are increasing rapidly in educational institutions because social networking usage is highest among those between 18 and 29 (Brenner \& Smith, 2013). According to a late 2012 study conducted by Pew Research Center, young adults are more likely to use social networking that any other age demographic. $83 \%$ of $18-29$ year olds surveyed use social networking sites. Facebook, Twitter and Instagram are the most popular sites among that demographic (Duggan \& Brenner, 2012). Due to this increased usage by young adults, it is not surprising that student-athlete usage of social networking continues to grow. A Fieldhouse Media survey on social media use by student-athletes conducted in 2012 found that $72 \%$ of athletes surveyed have a Twitter account with $97.4 \%$ using the site daily, $93.5 \%$ have a Facebook account, and $64.81 \%$ have an Instagram account (DeShazo, 2013). 
Social networking monitoring programs were established to assist efforts to protect schools and other organizations from damaging information released online. When a student-athlete provides harmful information via social media, negative implications are possible for both the athlete and his institution. The University of North Carolina - Chapel Hill (UNC) became a cautionary tale for those concerned with social networking after the NCAA's Committee on Infractions released the following statement in their report.

"During 2009 and 2010, the institution failed to monitor the conduct and administration of the football program. Specifically, the institution failed to a) monitor the activities of former student-athlete $\mathrm{A}$; and $\mathrm{b}$ ) investigate information it obtained suggesting that studentathlete 5 may have been in violation of NCAA legislation." (Infractions, 2012)

Student-athlete 5 is widely assumed to be Marvin Austin, a former defensive back for UNC. On May 29, 2010 Austin sent out this tweet: "I live in club LIV so I get the tenant rate. bottles comin [sic] like its [sic] a giveaway." His words were referencing a song from rap artist, Rick Ross; however, this simple tweet led to an investigation by the NCAA and media sources regarding the possibility of any impermissible benefits. The NCAA eventually uncovered a series of potential violations due to improper benefits based on information provided via Austin's Twitter account containing 2,400 other tweets at the time (Giglio, 2010). While the information found through social media was only a small portion of the violations present at UNC, the NCAA's Committee on Infraction's report cautioned other universities to be wary of studentathlete social media use.

This paragraph signaled that a University has some responsibility to monitor the social media activity of its studentathletes. If $\mathrm{UNC}$ had monitored in this instance, these violations may have been uncovered early enough to allow for self-reporting and/or lesser penalties. UNC took this warning seriously by establishing 
social media policies for student-athletes and the football team later football student-athletes from using Twitter.

As a result of the issues caused by social media for UNC and other institutions, many universities have established social media policies to protect the reputation of both the student-athlete and the university. These monitoring policies are often in attempt to maintain institutional control (Hopkins, Hopkins, \& Whelton, 2013). In a 2011 study, Jimmy Sanderson examined the social media policies at Division I institutions. At the time, 159 institutions had social media policies in their student-athlete handbook and these social media specific policies were between 33 and 1,037 words in length (Sanderson, 2011). There are larger social media policies at universities that affect faculty and staff; however, the policies found within student-athlete handbooks can be used to punish and contain the monitoring language that may conflict with established privacy law. These policies typically contained language designed to protect the student-athlete by prohibiting certain content and warning student-athletes of online dangers including predators looking to expose bad behavior (Sanderson, 2011). This emphasis on prohibited conduct instead of education has a secondary effect of creating the need for monitoring.

While the social media policies typically alert the studentathlete about the dangers of social media, the warnings issued concerning inappropriate behavior tend to be vague. Taking a broad approach to defining inappropriate content on social media allows for universities to monitor all social media communications. This strategy allows, teams, and by extension, athletic departments and universities have a long reach to punish any content deemed to be detrimental and even remove potential offending content. Monitoring can be done in-house by coaches, other athletic staff, or conducted by third-party companies that specialize in monitoring. 16 of the 159 policies examined by Sanderson specifically required student-athletes to send friend requests to coaches or athletic department personnel in charge of monitoring (Sanderson, 2011). 
The lack of specific definition for inappropriate content may allow for expanded monitoring efforts but it also makes it difficult for student-athletes to recognize what they should and should not say in a public forum like Twitter. A surprising number of studentathletes have admitted to posting something inappropriate on these websites. The 2012 Fieldhouse Media survey defined inappropriate material as anything racial, sexual, violent, profane, or in support of drug/alcohol use. Of those surveyed, $23.1 \%$ of student-athletes admitted to posting something inappropriate on Twitter in comparison to the $22.3 \%$ on Facebook and $14.3 \%$ on Instagram (DeShazo, 2013). While this survey is only a small sampling of student-athletes using social media, it would not be difficult to predict similar usage among the entire group. Around $20 \%$ does not equal a large problem in terms of inappropriate material, but remember; this survey only calculated what those student-athletes perceived to be inappropriate. Without proper education or monitoring of social media activity of student-athletes, the problem could grow exponentially and create issues for the athlete and the institution they represent.

There are three main methods for regulating social media usage typically employed by athletic departments: bans, guidelines without monitoring and policies that include monitoring. Bans are effective because they completely limit student-athlete access to these sites. A ban also protects a student-athlete from scrutiny by the media or fans/rivals. Typically, athletes do not complain about these bans because playing sports is more important to them than social networking. T.J. Yates, former UNC quarterback, once famously tweeted " $[\mathrm{t}] \mathrm{o}$ Tweet or play football???? That's an easy decision.... Bye Bye twitter I am really gonna miss you guys....see you in about 3 months" after a Twitter ban was imposed for UNC football (Walsh, 2010). However, not all student-athletes are committing violations or are using social networking to post inappropriate information. These sites do come with a lot of positives, like free publicity for an organization. Further, blanket bans can lead to a 
charge of limiting free speech and privacy as discussed in section II of this article.

Social networking guidelines are about education. These guidelines educate students on how to properly act and respond on social networking sites. Research in this area was limited to Division I guidelines and policies available online for public access. Of those guidelines found, several common themes emerged. Guidelines typically warn student-athletes of the dangers associated with social media, urging them to use caution and to think before they tweet. They're also warned against posting any personal information that could be used against them, including information that could be used by scam artists or embarrassing information that you wouldn't want to be made public. Some guidelines even go as far as warning student-athletes about how their actions online can affect the university (Sanderson, 2011). Several of the guidelines sampled for this article discussed protecting copyrighted works by not posting videos or pictures without permission (Maryland Athletics, 2011). Additionally, one policy even warned about potential NCAA violations that could occur if a student-athlete posted a comment about a recruit on social networking. Guidelines are not entirely effective because they are informative but lack any regulatory abilities. If students are able to pinpoint that their activities are inappropriate, yet still post the information on social networking, this signifies that guidelines alone will be largely ineffective.

The most effective, and unfortunately, least used method of social media regulation is to have a policy that includes monitoring of social media accounts by either a coach, administrator or third party organization. While monitoring has become quite common, it often does not come with social media training on what is appropriate behavior. As noted by Sanderson, social media guidelines and policies warn of bad behavior but rarely discuss the effective methods for using these sites (Sanderson, 2011). Social media policies are similar to guidelines in that they both provide limitations to behavior on social networking. Policies, however, typically also come as a binding contract between the university and 
the student-athlete. The contract connected to these social media policies often highlights that student-athletes can be punished for inappropriate conduct considered detrimental to the team, the school or the NCAA. To punish for inappropriate conduct and material, monitoring is needed. However, this type of monitoring is not likely to eliminate the problem but instead create tension and concern that could lead to more stringent monitoring.

A September 2012 survey conducted by the College Sports Information Directors of America (CoSIDA) highlighted how athletic departments were educating student-athletes on social media use and what monitoring procedures are in place. $55.3 \%$ of those who responded to the CoSIDA survey or 224 schools do monitor student-athlete activity on social media. Monitoring is usually done by members of the athletic department, whether it is the sports information director, a compliance officer or a team coach. Most monitoring is handled manually as only $3.8 \%$ (17 schools) said that they used monitoring software to follow student-athletes.

Interestingly enough, while schools are willing to monitor and punish students for their activity on social media, few schools are using their resources to educate the students beyond the required guidelines or policies. $56 \%$ of the responding schools (over 450 responded to the survey) did not offer any social media training to their students (College Sports Information Directors of America, 2013).

The results of this CoSIDA survey highlight that the current emphasis regarding social media regulation is on monitoring. Simply monitoring the actions of student-athletes online does not remove the threat of improper conduct being linked to the university. Instead, schools have begun to monitor and remove content from social media sites along with punishment if a social media policy is in place. Over $50 \%$ of the schools removed a social media post from a coach or a student-athlete during the last 12 months, according to the CoSIDA survey. $11 \%$ did it more than 10 times during the same time period (College Sports Information Directors of America, 2013).

The active removal of information on social media along with any 
potential punishment based on information posted could lead to conflict with an individual's privacy rights. To effectively monitor social media, athletic departments must be wary of current privacy laws and the associated trends. If social media monitoring is not done in a legal manner, then those departments have only sidestepped one problem to walk into another.

\section{Privacy Law and Social Media Regulation}

The need for privacy laws is indirectly connected to the growth of journalism. One of the earliest calls for privacy law arose from a lawsuit in the mid-1800s. In England, Prince Albert sued defendant Strange to prevent the publication of a series of etchings drawn for the sake of amusement by Prince Albert and Queen Victoria that were meant to be kept private. These etchings were kept in the Queen's private apartment and were reportedly locked away before they were in defendant Strange's possession. The court concluded that the property in question was entitled to some form of privacy because of its personal nature (Prince Albert v. Strange). While this is a decision from the English high court, which has no bearing on law in the United States, this case was discussed at length in a law review article written by Louis Brandeis and Samuel Warren that is considered by many to be the first declaration of the right to privacy in the U.S.

Within the article, Brandeis and Warren discussed how new inventions (the photograph in particular) must also lead to new law to protect the privacy of an individual and the "right to be let alone." This right, however, is not all encompassing. Material that is of a public interest still has the right to be published. Further, this right also does not prohibit the disclosure of material that was first published by the individual claiming a privacy right. Brandeis and Warren understood the need for news, but believed that information that is meant to be private shall be allowed to remain so. Like any law, the right of privacy requires discussion and interpretation to fulfill the required protections. Our interest in others is a common thread in our society, but we must make sure that that desire for 
information continues to protect the privacy of others and be mindful of how new technology could potentially invade the "right to be let alone." (Warren \& Brandeis, 1891)

As technology and society progresses, so to must the law of privacy. If we followed a literal interpretation of the law as presented by Brandeis and Warren, then all social media would be considered unprotected material. They advocated for the protection of privacy to cease once materials were published. Posting online, even if it is only seen by a small group of people, would lead to no protection. The law has instead begun to adapt to allow for protection of these websites even though publication is at the heart of social media simply because it is possible to limit the accessibility of these accounts. If the information is shared with certain individuals, it should be given the same right of privacy that would be granted if it were a private letter between individuals. Typically, the First and Fourth Amendment of the United States Constitution have also been used to protect speech and privacy on a federal level. This article, however, focuses on state legislation instead because of its applicability to both public and private institutions.

When social media first became popular, many saw its usefulness as a means to gain information about other people. That could be something as simple as "facebook stalking," a slang term used to describe using social media to find out information about someone you may or may not know. Or it can be used for more informative purposes, like as a source of material during a background check accompanying a job application/interview process. A study from 2012 noted that two in five employers use social media to screen potential candidates for positions (Kwoh, 2012). These employers are using social media to investigate employees in a similar manner to the way it is applied in college athletics: to screen for any inappropriate posts, pictures or videos that could be detrimental to the individual and the organization.

In the spirit of protecting privacy, many state legislatures have adopted laws limiting employer access to social media accounts. Maryland was the first state to pass this type of legislation 
and sign it into law in May of 2012. The purpose of this legislation was to prevent employers from requesting the social media user names and passwords of employees and potential employees as a condition of employment (House Bill 964, 2012). The legislature focused on the idea that a person should not have to endure a loss of privacy just to retain employment, which revolves back to Brandeis and Warren's central thesis of the "right to be let alone." (Warren \& Brandeis, 1891)

Because employers are not the only group using social media to gain information, similar legislation is now being targeted towards educational institutions. As of May 2014, there are 10 states with some form of social media privacy law for educational institutions: Arkansas, California, Delaware, Illinois, Michigan, New Jersey, New Mexico, Oregon, Utah, and Wisconsin (National Conference of State Legislatures, 2014). Delaware was the first state to enact a law prohibiting excessive social media monitoring by post-secondary institutions. This law prohibits the request or requirement that any student or prospective student disclose their social media password or any other personal information to gain access to their accounts. Schools are also prohibited from asking students to log into their social media sites in the presence of an agent of the institution for the purposes of monitoring. They cannot add tracking software to a student's device nor can they request or require that a student add a representative of the institution to their social media network. Finally, Delaware law prohibits accessing a student's social media site indirectly through a third party who is connected to the student via social media (House Bill 309, 2012).

Using Delaware's social media access legislation as an example, legislatures seem to take issue with monitoring only when that monitoring capability directly forces action from the student or employee. The greater focus of this legislation appears to be the desire to protect communication made from personal and private devices. By prohibiting certain actions only and not establishing a blanket ban on monitoring, the Delaware law seemingly justifies an organization or athletic department's desire to be aware of an 
affiliated employee or student's social media activity but limits the reach of their monitoring capabilities.

The remaining existing social media legislation also focuses on themes reminiscent of Brandeis and Warren by protecting the right of the individual to be let alone. Each existing law, like Delaware, prohibits the request or requirement of passwords or other personal information, like their username along with requiring accessing these sites in the presence of an employee of the postsecondary institution. There are some differences between states as well. Some states explicitly state that these laws do not prohibit the finding of information that is publicly available (Senate Bill 422, 2013). Since the laws vary by state, the best practice of an administrator in charge of social media monitoring is to determine how the law applies in your state. Even if your state currently doesn't have this type of legislation, there is a growing trend towards social media privacy and diligence is the best way to protect yourself and your organization.

What do these laws mean for the athletic department attempting to monitor social media for the protection of their athletes and their universities?

\section{How Does Privacy Legislation Affect An Organization's Response to Social Media Usage by Student-Athletes?}

The main concern for athletic departments and teams seeking to monitor social media activities conducted by their student-athletes should be whether the type of regulation used is legal. No studentathlete has filed a lawsuit to protect their social media privacy; however, the potential success of those arguments has forced others in similar situations to settle.

Recently, the Minnewaska Area school district in Minnesota paid seventy thousand dollars to a former sixth grade student who was punished over disparaging remarks she made on Facebook from her home computer. When school officials received a complaint about this online behavior, the student, Riley Stratton, was forced to give officials her Facebook password or face detention. Fearing 
punishment, she relented, but her family with the help of the American Civil Liberties Union, later sued the school district claiming a violation of free speech and privacy (Benitez, 2014). While this case was ultimately settled, it does establish the viability of social media privacy cases. It is worth noting that social media legislation for student has been introduced by the Minnesota legislature before this case was settled. Minnesota also does not have active legislation controlling employer access to social media usernames and passwords (National Conference of State Legislatures, 2014). This is worth noting because the lack of specific legislation denying access to social media usernames and passwords will not preclude a viable invasion of privacy and violation of free speech lawsuit.

Focusing on the legality of the department's actions will help to avoid any problems in the future if a student-athlete should file a lawsuit in connection to their social media activities. For those athletic departments and teams in states who have yet to pass social media legislation connected to schools, there may be some hesitation to change tactics to comply with laws not yet in existence. However, change is coming. Within three years, 10 states discussed social media privacy for educational institutions and that were later signed into law. This does not include the multitude of states that continue to debate adding this type of legislation (National Conference of State Legislatures, 2014). Additionally, social media controversies involving student-athletes continue to grow, which should be a cause for concern in terms of monitoring and maintaining privacy. Athletic departments and teams do not need to cease all managing responses when it comes to student-athlete use of social media in the wake of changing legislation. Even with the prevailing culture towards enhancing privacy, social media monitoring is legal, but certain parameters must be followed to stay on the right side of the law.

As discussed in section I, there are three current trends for how athletic departments and teams handle the use of social media by student-athletes. Since each of these trends create different results 
in terms of monitoring and privacy regulation, social media legislation will affect the trends in different fashions.

First, social media bans call for a blanket prohibition against social networking sites by student-athletes. These blanket bans stop all social networking usage and thus limit the need for monitoring. Because no monitoring is attached, any organization utilizing a social media ban does not need to be concerned about educational institution access to social media legislation. These bans could potentially run afoul of the law in another way due to First Amendment right to free speech concerns; however, the documents voluntarily signed by student-athletes prior to participation minimize any potential First Amendment claim (Penrose, 2013). While this article focuses on privacy legislation, an organization should take the time to note and be aware of other legal complications connected to regulating student-athlete usage of social networking websites.

Social media guidelines are similar to social media bans due to the lack of connection to privacy legislation. Typically, social media guidelines are used to warn student-athletes of the dangers associated with using social networking sites. If these guidelines are only being offered as an educational resource to make studentathletes aware of who is watching their activity on social media, then it can be viewed as only a cautionary and educational notification. However, if there is any punishment or consequences from the university attached to the social media policy, then the likelihood increases that athletic staff is monitoring these sites. That monitoring is exactly what access legislation attempts to limit and should be considered when developing the guidelines.

For those policies that explicitly state that monitoring will be conducted, organizations must make sure that their monitoring is conducted in a legal manner. This caution should be used whether or not the school or university is located within a state that has existing social media legislation directed at educational institutions. The Minnewaska school district in Minnesota found themselves in a situation where a legal challenge to their social media policy for students was initially successful (R.S. et al v. Minnewaska, 2012). 
They did settle the case out of court to avoid further responsibility, but the fact that the case did survive an initial motion for summary judgment highlights the growing trend towards privacy even in states without specific social media privacy legislation.

A successful social media monitoring policy should focus its monitoring efforts on publicly available information. Of the ten social media access laws that applies to educational institutions, each one prohibits requests or requirements for social media usernames or passwords. Asking for this information is precisely why social media legislation was enacted. It has been repeatedly considered a violation of privacy when this information must be provided as a condition of employment or participation (Poerio \& Bain, 2012). Along the same lines, requiring or requesting student-athletes to follow or friend one of the team's coaches or administrators can create legal problems for an organization. This too is will likely be considered a violation of privacy because the rule applies to all student-athletes, regardless of whether their accounts are public or private.

When Brandeis and Warren wrote on the basis of privacy law in this country, the main purpose was to protect information that others wished to be kept private. All social media users have the option of limiting access to their accounts through privacy controls. If a university was to require or request access to these locked accounts, it would be a direct violation of their privacy because the methods used to limit access would become worthless. It does not matter that many of these student-athletes are willing to give up their privacy for the sake of participation. All it takes is one studentathlete complaint about privacy to derail an entire team or department's social media monitoring goals. Currently, there are no lawsuits filed challenging the right of privacy in relation to social media monitoring and associated punishments in the post-secondary educational setting, but that doesn't mean a university can completely ignore the possibility especially as social media related controversies grow. By carefully tailoring social media monitoring policies within the parameters of existing legal trends, an organization will be able to achieve the results of monitoring with 
minimal threat of liability from both NCAA regulations and changing state law.

Based on current law, universities can avoid violation of privacy claims by focusing on publicly available information on social media sites. This method does require conducting searches for student-athlete social media accounts that could be an extensive and tedious process, but allows you to achieve similar results. According to the 2012 Fieldhouse Media survey on social media use by studentathletes, $64.1 \%$ of student-athletes have a public Twitter account. Student-athletes tend to use the privacy settings more on Facebook and Instagram, with $96 \%$ using the privacy settings on Facebook and $60 \%$ private accounts on Instagram (DeShazo, 2013). The use of privacy settings may make monitoring more difficult, but the majority of social media related violations have been connected to Twitter. Additionally, social media accounts are often linked. If a student-athlete posts a photo to Instagram, a link could be created through their Facebook or Twitter account that allows you to see the photo.

In some instances, universities may be able to streamline this process with the use of a third-party monitoring company. These sites take on the work of monitoring the activity of student-athletes and may be able to gain access to private accounts if those students willingly accept invites from those working for third-party monitoring organizations. You must use these sites with caution. For example, in Utah, use of these third-party monitoring organizations is considered an illegal way to monitor student-athletes. Beyond that, each team and university also needs to make sure that these organizations are protecting the privacy of student-athletes in the same manner you would use with in-house monitoring. Social media monitoring does not need to be a particularly invasive process because the majority of information is publicly available.

\section{Conclusion}

As social media usage grows in our society, so too have concerns regarding privacy increased. The right to privacy initially 
began as a method to protect information that others wished to be kept private with publicly posted information not considered for privacy regulation. Social media provides complication because the whole purpose of these sites is to publish information to be seen by others. Law is quickly catching up to technology and providing a challenge for those who would like to be able to monitor the social media activity of their representatives. The growing legal trend in relation to social media is to protect the privacy of social media users from other organizations. In general, any request or requirement of social media access is being met with legislation declaring this to be a violation of privacy.

The original concerns associated with social media for athletic organizations are still present. Student-athletes are often prone to make the mistakes of youth, which are further amplified and publicized through social media. A cautious team or athletic department must be concerned about social media activity, but that concern must proceed with caution. Social media monitoring is legal when used properly. Even if the state where the university is located currently does not have social media legislation, whether that means no existing legislation entirely or no legislation applicable to educational institutions, an organization is best served by limiting their monitoring capabilities as a means of protecting privacy interests. Focusing on publicly available accounts and information avoids the privacy concerns because anything made public cannot assume the same right of privacy available to locked accounts. Additionally, this monitoring must be done through searches instead of requests or requirements from student-athletes to share their information with the team or athletic department. This method is more tedious but can provide the same information in a legally responsible manner.

Social media monitoring does not need to be a complex and stressful process for teams and athletic departments. When monitoring is combined with educating student-athletes about the dangers of social media, you can minimize the risk of potentially damaging information being published online. Student-athletes need 
to be aware of the fact that anyone can see what they post online, especially on a publicly available account. Monitoring by athletic teams or by staff connected to the athletic department will help to make them more cautious and aware of their actions. Further, when these assigned social media monitors stick to publicly available information, you can prevent or manage the information more likely to be damaging while maintaining a safe respect for an individual's right to privacy. 


\section{References}

Benitez, G. (2014, March 28). ABC News. Retrieved from School District Pays $\$ 70 \mathrm{~K}$ to Settle Lawsuit Over Girl's Facebook Posts: http://abcnews.go.com/US/school-district-pays-70ksettle-lawsuit-online-posts/story?id=23094873

Brenner, J., \& Smith, A. (2013, August 5). 72\% of Online Adults are Social Networking Site Users. Retrieved from Pew Research Center: http://pewinternet.org/Reports/2013/socialnetworking-sites.aspx

Browning, B., \& Sanderson, J. (2012). The Positives and Negatives of Twitter: Exploring How Student-Athletes Use Twitter and Respond to Critical Tweets. International Journal of Sport Communication, 503-521.

Sherman, E. (2014, April 14). Many Twitter users don't tweet, finds report. Retrieved from CBS Money Watch: http://www.cbsnews.com/news/many-twitter-users-donttweet-finds-report/

Staples, A. (2012, January 24). For top football recruits, behavior on social media has consequences. Retrieved from Sports Illustrated: http://sportsillustrated.cnn.com/2012/writers/andy_staples/01 /24/recruits.social.media/

Browning, B, \& Sanderson, J. (2013). Training Versus Monitoring: A Qualitative Examination of Athletic Department Practices Regarding Student-Athletes and Twitter. Qualitative Research Reports in Communication, 105-111.

College Sports Information Directors of America. (2012, March 21). CoSIDA Survey Results: The state of crisis communications in college athletics. Retrieved from http://www.cosida.com/news.aspx?id=3603 
College Sports Information Directors of America. (2013, March 13). 2013 CoSIDA Membership Survey: Social Media Training for Student-Athletes and Coaches. Retrieved from http://cosida.com/media/documents/2013/3/2013_CoSIDA_S urvey_Results_Final1.pdf

DeShazo, K. (2013, March 11). Social Media Use of Student Athletes [survey results]. Retrieved from Fieldhouse Media: http://www.fieldhousemedia.net/social-media-use-of-studentathletes/

Duggan, M., \& Brenner, J. (2012). The Demographics of Social Media Users . Pew Research Center.

Giglio, J. (2010, July 20). Austin's Twitter account sheds light on UNC player. Retrieved from News Observer: $\mathrm{http} / / /$ blogs.newsobserver.com/accnow/austins-twitteraccount-provides-clues-in-ncaa-probe-at-unc

Gormley, K. (1992). One Hundred Years of Privacy. Wisconsin Law Review.

Hopkins, J. P., Hopkins, K., \& Whelton, B. (2013). Being Social: Why the NCAA Has Forced Universities to Monitor StudentAthletes' Social Media. University of Pittsburgh Journal of Technology Law \& Policy, 13 PGH. J. Tech. L. \& Pol'y 1.

House Bill 309 (2012). Delaware

House Bill 964 (2012). Maryland

House Bill 1902 (2013). Arkansas

House Bill 2654 (2013). Oregon

Infractions, N. C. (2012, March 12). University of North Carolina, Chapel Hill Public Infractions Report. Retrieved from Chronicle of Higher Education: http://chronicle.com/blogs/ticker/files/2012/03/UNC.pdf

Internet Privacy Amendments. House Bill 100 (2013). Utah Internet Privacy Protection Act. 2012 Mich. Acts 478. 28

Dec. 2012 
Kwoh, L. (2012, October 29). Beware: Potential Employers are Watching You. Retrieved from Wall Street Journal: http://online.wsj.com/article/SB10000872396390443759504 577631410093879278.html

Maryland Athletics: Social Media Guidelines for Student-Athletes. (2011, October 13). Retrieved from http://www.washingtonpost.com/r/20102019/WashingtonPost/2011/10/13/CapitalBusiness/Graphics/ Student $\% 20$ Athlete\%20Social\%20Media\%20Guidelines.pdf

Michigan Athletics: Social Media Guidelines. (n.d.). Retrieved from http://www.annarbor.com/University $\% 20$ of $\% 20$ Michigan $\% 2$ 0social\%20media\%20guidelines\%20for\%20athletes.pdf

National Conference of State Legislatures. (2013, January 17). 2012 Legislation relating to employer access to social media usernames and passwords. Retrieved from http://www.ncsl.org/issues-research/telecom/employeraccess-to-social-media-passwords.aspx

National Conference of State Legislatures. (2013, September 12). Employer Access to Social Media Usernames and Passwords 2013. Retrieved from http://www.ncsl.org/issuesresearch/telecom/employer-access-to-social-mediapasswords-2013.aspx

National Conference of State Legislatures. (2014, April 10). Employer Access to Social Media Usernames and Passwords 2014. Retrieved from http://www.ncsl.org/research/telecommunications-andinformation-technology/employer-access-to-social-mediapasswords-2013.aspx\#2014

Oregon State University. (n.d.). Social Media Tips. Retrieved from http://oregonstate.edu/main/social-media-guide

Park University Athletics Guidelines for the Use of Social Media. (n.d.). Retrieved from http://www.parkathletics.com/piratepost/park_university_athl etics_social_media_guidelines.pdf 
Patterson, C. (2013, May 10). Columbia officials release statement on hate crime, Twitter use. Retrieved from CBS Sports: http://www.cbssports.com/collegefootball/blog/eye-oncollege-football/22225511/columbia-officials-releasestatement-on-hate-crime-twitter-use

Penrose, M. (2013). Outspoken: Social Media and the Modern College Athlete. The John Marshall Law School Review of Intellectual Property Law. 12 J. Marshall Rev. Intell. Prop. L 509.

Poerio, J. M., \& Bain, L. E. (2012). Social Media in the Workplace: Employer Protections versus Employee Privacy. Retrieved from American Bar Association:

http://www.americanbar.org/publications/international_law news/2012/fall/social_media_workplace_employer_protectio ns_versus_employee_privacy.html

Poore, M. (2013). A Call for Uncle Sam to Get Big Brother Out of Our Knickers: Protecting Privacy and Freedom of Speech Interests in Social Media Accounts. Northern Kentucky Law Review, 40 N. Ky. L. Rev. 507.

Prince Albert v. Strange, 41 Eng. Rep. 1171(1849). Public Act 098-0129 (2013). Illinois Publishing to Twitter from Facebook pages. (n.d.). Retrieved from Facebook:

http://blog.facebook.com/blog.php?post=123006872130

R.S. v. et al v. Minnewaska Area School District No. 2149 et al, Civ. No. 12-588 (MJD/LIB) (2012).

Sanderson, J. (2011) To Tweet or not to tweet....: Exploring Division I athletic departments' social-media policies. International Journal of Sport Communication, 4, 492-513. Schwab, F. (2013, May 9). Report: Columbia football players' offensive tweets revealed after player charged with hate crime. Retrieved from Yahoo Sports: http://sports.yahoo.com/blogs/ncaaf-dr-saturday/columbiafootball-players-racist-homophobic-tweets-revealed-player170746947.html 
Senate Bill 223 (2013). Wisconsin

Senate Bill 422 (2013). New Mexico

Senate Bill 1349 (2012). California

Sherman, E. (2014, April 14). Many Twitter users don't tweet, finds report. Retrieved from CBS Money Watch:

http://www.cbsnews.com/news/many-twitter-users-donttweet-finds-report/

Browning, B., \& Sanderson, J. (2012). The Positives and Negatives of Twitter: Exploring How Student-Athletes Use Twitter and Respond to Critical Tweets. International Journal of Sport Communication, 503-521.

Sherman, E. (2014, April 14). Many Twitter users don't tweet, finds report. Retrieved from CBS Money Watch: http://www.cbsnews.com/news/many-twitter-users-donttweet-finds-report/

Staples, A. (2012, January 24). For top football recruits, behavior on social media has consequences. Retrieved from Sports Illustrated:

http://sportsillustrated.cnn.com/2012/writers/andy_staples/01 /24/recruits.social.media/

Using Twitter with Facebook. (n.d.). Retrieved from Twitter:

https://support.twitter.com/articles/31113-using-twitter-with facebook

Walsh, M. (2010, October 18). Twitter banned for UNC football. Retrieved from Daily Tar Heel: http://www.dailytarheel.com/article/2010/10/twitter_banned_ for unc football

Warren, S., \& Brandeis, L. (1891). The Right of Privacy. Harvard Law Review. 